\title{
Polysaccharides from Liriopes Radix ameliorate streptozotocin-induced type I diabetic nephropathy via regulating NF-KB and p38 MAPK signaling pathways
}

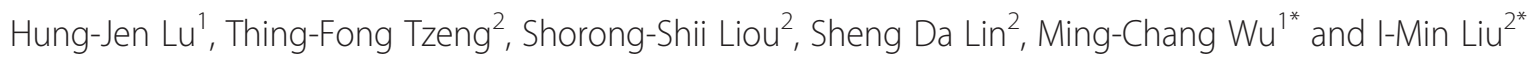

\begin{abstract}
Background: The polysaccharides from Liriopes Radix (PSLR) has been indicated to ameliorate insulin signaling transduction and glucose metabolism. We aimed to investigate whether PSLR exerts an ameliorative effect on renal damage in diabetes induced by streptozotocin.

Methods: Diabetes was induced with STZ (60 mg/kg) by intraperitoneal injection in rats. Two weeks after STZ injection, rats in the treatment group were orally dosed with PSLR (200 and $300 \mathrm{mg} / \mathrm{kg} /$ day for 8 weeks. The normal rats were chosen as nondiabetic control group. Changes in renal function-related parameters in plasma and urine were analyzed at the end of the study. Kidneys were isolated for pathology histology, immunohistochemistry, and Western blot analyses.
\end{abstract}

Results: Diabetic rats exhibited renal dysfunction, as evidenced by reduced creatinine clearance, blood urea nitrogen and proteinuria, along with marked elevation in the ratio of kidney weight to body weight. All of these abnormalities were significantly reversed by PSLR. The histological examinations revealed amelioration of diabetes-induced glomerular pathological changes following treatment with PSLR. The less protein expressions of renal nephrin and podocin in diabetic rats were increased following treatment with PSLR. PSLR reduced the accumulation of ED-1-expressing macrophages in renal tissue of diabetic rats. PSLR almost completely abolished T cells infiltration and attenuated the expression of proinflammatory cytokines. PSLR treatments not only reduced the degradation of inhibitory kappa B kinase, but also downregulated the protein expression of nuclear factor kappa B (NF-kB) and p38 mitogen-activated protein kinase (MAPK) in diabetic kidney.

Conclusions: The results suggest that the renal protective effects of PSLR occur through improved glycemic control and renal structural changes, which are involved in the inhibition of NF-KB and p-38 MAPK mediated inflammation.

\section{Background}

Diabetes mellitus is a metabolic disease usually characterized by the classic triad of polydipsia, polyuria and polyphagia, consequences of homeostasis disruption due to impaired glucose metabolism [1]. Diabetic nephropathy $(\mathrm{DN})$, the second most prevalent diabetes-

\footnotetext{
* Correspondence: mcwu@mail.npust.edu.tw; iml@tajen.edu.tw 'Department of Food Science, College of Agriculture, National Pingtung University of Science and Technology, Neipu Township, Pingtung County, Taiwan

${ }^{2}$ Department of Pharmacy \& Graduate Institute of Pharmaceutical Technology, Tajen University, Yanpu Township, Pingtung County, Taiwan
}

associated complication inferior to cardiovascular disorders, impaired the renal function of diabetes patients and therefore cost appreciable medical labor and resource for DN management annually [2]. Although DN is traditionally considered a non-immune disease, accumulating evidence now indicates that immunologic and inflammatory mechanisms play significant roles in its development and progression [3]. It also suggested the development of DN was associated with the activation of several signal pathways, including nuclear factor kappa B (NF-KB) and mitogen-activated protein kinase (MAPK) [4]. Genetic and pharmacological approaches 
that reduce inflammation in DN have not only enhanced our understanding of the disease pathophysiology, but have also shown promise as potential therapeutic strategies.

Many herbal extracts or derivatives have been documented in traditional Chinese medicine (TCM) as having clinical effectiveness in treating diabetes mellitus [5]. The tuberous root of Liriope spicata (Liliaceae) were recorded as Liriopes Radix in the Pharmacopeia of the People's Republic of China, are frequently used as "maidong" in prescriptions for the treatment of diabetes mellitus. Chemical studies have shown that this plant mainly includes saponins, polysaccharide and homoisoflavonoidal compounds [6]. It has been reported that the water extract and crude polysaccharides obtained from Liriopes Radix had considerable hypoglycemic effects [7]. The polysaccharides from Liriopes Radix (PSLR) caused more marked activation on insulin signaling transduction in type 2 diabetic mice than the effects produced by water extract has been also demonstrated [8]. Liriopes Radix is valued for the ability to promote glucose homeostasis, and it may therefore be utilized as an adjuvant therapy in the control of diabetic complications. The potential preventive effects of PSLR on DN in diabetic rats has been reported to mediate by down-regulating the system of advanced glycation end products-receptor for advanced glycation end products [9]. Actually, anti-inflammatory potential of Liriopes Radix has been identified [10]. Since the inflammatory process is also involved in the pathogenesis of $\mathrm{DN}$, there is a possibility that PSLR may ameliorate DN by suppression of renal inflammation, but this has never been explored.

Without intervention, approximately $80 \%$ of patients with type 1 diabetes and $20-40 \%$ of those with type 2 diabetes develop overt nephropathy in 10-15 years [11]. The present studies were thus designed to further elucidate whether the renopreventive effects of PSLR be responsible for the alleviation of diabetic renal inflammation utilizing streptozotocin-induced diabetic rats (STZ-diabetic rats) as a type-1 diabetic animal model.

\section{Methods}

\section{Plant material and extraction}

The tuberous root of L. spicata was purchased from a local market in Pingtung County (Taiwan) on May 2012. Plant identification was done by Professor Hong T.Y. (the Department of Biotechnology, Collage of Pharmacy and Health Care, Tajen University). Random amplified polymorphic DNA analysis of Liriopes Radix supplied was also performed to identify DNA polymorphisms. The voucher specimen (Lot No. LS20120523) has been deposited in our laboratory.

Preparation of PSLS was performed according to the previous study [7]. The powdered material $(200 \mathrm{~g})$ was boiled in distilled water three times $(1: 4,1: 4,1: 2$, w/v),
$0.5 \mathrm{~h}$ each time. Each extract was then filtered and merged together. Phosphate buffer ( $\mathrm{pH} 5.91)$ and $0.6 \mathrm{~g}$ of papain (12 $\mathrm{u} / \mathrm{mg}$, Biosharp, USA) were added into the extracts and kept in water-bath $\left(45^{\circ} \mathrm{C}\right)$ for $2 \mathrm{~h}$ to remove proteins. After boiled for $5 \mathrm{~min}$, the extracts were stored overnight at $4{ }^{\circ} \mathrm{C}$ and filtered next morning. The filtrate was purified by using the mini pellicon system (ultrafiltration membrane Mw cut-off 1000, Millipore, USA) with $12 \mathrm{l}$ distilled water. The retentate portion was concentrated and then separated in DEAE-cellulose 52 columns to remove pigments. The water eluted solution was concentrated and finally lyophilized (Alpha 2-4, Christ, Germany) and obtained $53.2 \mathrm{~g}$ of PSLR from $200 \mathrm{~g}$ powdered material. The sugar content of PSLR was $98.1 \%$ determined by anthrone-sulfuric acid method at $625 \mathrm{~nm}$ using fructose as standard [12].

\section{Animal models}

Male Wistar rats (8-10 weeks of age, 200-250 g) were obtained from the Animal Center of National Cheng Kung University Medical College. To induce diabetes rats were given a single intravenous injection of $60 \mathrm{mg} / \mathrm{kg}$ streptozotocin (STZ; Sigma-Aldrich, Inc., Saint Louis, Missouri, USA). Animals were considered to be diabetic if they had plasma glucose concentrations of $350 \mathrm{mg} / \mathrm{dl}$ or greater, in addition to polyuria and other diabetic features. All studies were carried out two weeks after the injection of STZ. All animal procedures were performed according to the Guidelines for the Care and Use of Laboratory Animals of the National Institutes of Health (United States), as well as the guidelines of the Animal Welfare Act. These studies were conducted with the approval of the Institutional Animal Care and Use Committee (IACUC) at Tajen University (approval number: IACUC 100-29; approval date: December 22, 2011).

\section{Treatment protocols}

The selection of dosage regime for the present studies was according to the previous report that demonstrated administration with PSLR at 200 and $300 \mathrm{mg} / \mathrm{kg}$ for 4 weeks exerted potential effect in improving hyperglycemia in diabetic mice [9]. In order to obtain the significant effect of PSLR on improvement of DN, STZdiabetic rats were dosed by oral gavage once per day for eight weeks with PSLR doses of 200 or $300 \mathrm{mg} / \mathrm{kg}$ in a volume of $1.5 \mathrm{ml} / \mathrm{kg}$ distilled water. A vehicle-treated group of STZ-diabetic rats and normal rats was treated with $1.5 \mathrm{ml} / \mathrm{kg}$ distilled water only over the same treatment period. Animals received standard rat diet (Harlan Teklad, Madison, WI, USA; Cat. No. 2018) and water ad libitum throughout the entire treatment period. PSLR treatment was continued even though the plasma glucose of STZ-diabetic rats was lower than $350 \mathrm{mg} / \mathrm{dl}$ during the eight-week treatment period. The evening prior to blood 
sample collection animals were restricted to $3 \mathrm{~g}$ of chow (given at 18:00), which was consumed immediately, and thereafter had access to only water. The animals were transferred to metabolic cages (Shineteh Instruments Co., Ltd, Taipei, Taiwan) for urine collection 24 hours before sacrifice. Urine was collected under a layer of toluene (to inhibit bacteria growth) and stored at $4^{\circ} \mathrm{C}$ until analyzed. Toluene used had no detectable effect on the estimation of albumin and creatinine in the urines collected in the metabolism experiments.

At the end of the eight-week treatment, rats were sacrificed using an intraperitoneal injection of sodium pentobarbital $(50 \mathrm{mg} / \mathrm{kg})$. The kidneys were dissected and rinsed with cold isotonic saline and weighed. An index of renal hypertrophy was estimated by comparing the wet weight of the left kidney to total body weight. The cortical tissues from right kidney were stored immediately at $-80^{\circ} \mathrm{C}$ in liquid nitrogen for biochemical determinations and Western blot analyses. Other kidney tissues were fixed in $10 \%$ neutralized formalin for histology and immunohistochemistry.

\section{Blood sampling and analysis}

Blood sample of rats were centrifuged at 2,000 $\times g$ for 10 minutes at $4^{\circ} \mathrm{C}$, plasma was removed and aliquot for the respective analytical determinations. The diagnostic kit for determinations for plasma levels of glucose (Cat. No. COD12503) was purchased from BioSystem (Barcelona, Spain). The plasma creatinine $(\mathrm{Cr})$ concentration was determined by the commercial assay kit (Cat. No. 221-30) purchased from Diagnostic Chemicals Limited (Connecticut, USA). Blood urea nitrogen (BUN) was determined by kinetic reagent (Diagnostic Chemicals Limited, Cat. No. 283-30). Commercial enzyme-linked immunosorbent assay (ELISA) kits were used quantify glycosylated hemoglobin $\left(\mathrm{HbA}_{1 \mathrm{c}}\right)$ levels (Intergrated Bio Ltd., Taipei, Taiwan; Cat. No. CSB-E08140r). Kits for determination of plasma alanine aminotransferase (ALT; EC 2.6.1.2) (Cat. No. A524-780TM) and aspartate aminotransferase (AST; EC 2.6.1.1) (Cat. No. A559-780TM) concentrations were purchased from Teco Diagnostics (CA). Assays were performed according to the manufacturer's instructions. All experiments were performed in triplicate to ensure the accuracy of the observations.

\section{Analysis of urine parameters}

The 24-h urine collected from each diabetic rat and agematched control was centrifuged at 2,000 $g$ for $10 \mathrm{~min}$. Urinary albumin concentrations were measured by Nephrat II ELISA kit (Cat. No. NR002) obtained from Exocell, INC. (PA, PUA). The concentration of $\mathrm{Cr}$ in pooled urine samples was determined by the commercial assay kit (Diagnostic Chemicals Limited, Cat. No. 221-30). All analyses were performed in triplicate in accordance with the manuals provided by the manufacturers. Creatinine clearance $(\mathrm{Ccr})$ was calculated in individual rats as follows: $\mathrm{Ccr}=$ urine creatinine $\times$ urine volume/plasma creatinine $\times$ time [13].

\section{Renal cytokines determination}

Renal tissue was homogenized in $10 \mathrm{mmol} / \mathrm{L}$ Tris $-\mathrm{HCl}$ buffered solution ( $\mathrm{pH}$ 7.4) containing $2 \mathrm{~mol} / \mathrm{l} \mathrm{NaCl}$, $1 \mathrm{mmol} / \mathrm{l} \mathrm{EDTA}, 0.01 \%$ Tween 80, $1 \mathrm{mmol} / \mathrm{l} \mathrm{PMSF}$, and centrifuged at $9000 \times g$ for $30 \mathrm{~min}$ at $4^{\circ} \mathrm{C}$ [14]. The resultant supernatant was used for cytokine determination. The levels of proinflammatory and anti-inflammatory cytokines were estimated by performing ELISA using commercial kits. ELISA kits for the determination of tumor necrosis factor (TNF) $\alpha$ (Cat. No. ab46070), interleukin (IL)-6 (Cat. No. ab100772), and IL-10 (Cat. No. ab100764) were obtained from Abcam Inc. (Cambridge, MA, USA). Samples were assayed in triplicate according to manufacturer's instructions. The protein concentrations of kidney filtrate were determined according to the previous method using BSA as a standard [15].

\section{Renal histological analysis}

Renal tissues were fixed with 10\% neutral formalin phosphate buffer, dehydrated through a graded alcohol series and embedded in paraffin, cut into $4 \mu \mathrm{m}$ sections and stained with hematoxylin and eosin (H\&E). The sections were examined with light microscopy by an experienced pathologist and micrographs from six glomerulums were obtained randomly with magnification of $400 \times$. Mean glomerular volume was determined from the mean glomerular capillary tuft area $\left(\mathrm{A}_{\mathrm{G}}\right)$ by light microscopy of PAS sections. The areas were determined by light microscopy and analyzed by dedicated software (Analysis 3.0, Soft Imaging System, Münster, Germany) as the average area of 50 glomerular profiles (the capillary tuft omitting the proximal tubular tissue and Bowman's capsule) for each animal. Glomerular volume (GV) was calculated using the formula $\mathrm{GV}=\beta / \mathrm{k} \times\left(\mathrm{A}_{\mathrm{G}}\right)^{3 / 2}$, where $\mathrm{GV}$ is glomerular volume, $\beta=$ 1.38 , which is the shape coefficient for spheres (the idealized shape of glomeruli), $\mathrm{k}=1.1$, which is a size distribution coefficient, and $\mathrm{A}_{\mathrm{G}}$ is the glomerular capillary tuft area [16]. The index of mesangial expansion was scored by a quantitative estimate of the mesangial zones width in each glomerulus, expressed as a function of the total glomerular area [17]: 0, normal glomeruli; 1, matrix expansion occurred in up to $50 \%$ of a glomerulus; 2 , matrix expansion occurred in $50-75 \%$ of a glomerulus; 3 , matrix expansion occurred in $75-100 \%$ of a glomerulus.

\section{Immunohistochemistry}

Formalin-fixed, paraffin-embedded kidney tissue sections were used for immunohistochemical staining. After deparaffinization and hydration, the slides were 
washed in Tris-buffered saline (TBS; $10 \mathrm{mmol} / \mathrm{L}$ Tris $\mathrm{HCl}, 0.85 \% \mathrm{NaCl}, \mathrm{pH} 7.2$ ). Endogenous peroxidase activity was quenched by incubating with the slides in methanol and $0.3 \% \mathrm{H}_{2} \mathrm{O}_{2}$ in methanol. After overnight incubation with Mouse monoclonal anti-rat monocyte/ macrophage antibody (anti-ED-1) (sc-59103; Santa Cruz Biotechnology Inc. CA, USA) at $4^{\circ} \mathrm{C}$, the slides were washed in TBS and horseradish peroxidase (HRP)-conjugated goat anti-mouse secondary antibody was then added and the slides were further incubated at room temperature for $1 \mathrm{~h}$. The slides were washed in TBS and incubated with diaminobenzidine tetrahydrochloride as the substrate, and counterstained with hematoxylin. A negative control without primary antibody was included in the experiment to verify the antibody specificity. Intraglomerular ED-1-positive cells were counted in 200 glomeruli/group under 400-fold magnification.

\section{Western blotting}

Protein extraction of isolated kidney was performed as follows [18]. The sample was homogenized in ice-cold in $1 \mathrm{ml}$ of hypotonic buffer A $[10 \mathrm{mmol} / \mathrm{l}$ HEPES (pH 7.8), $10 \mathrm{mmol} / \mathrm{l} \mathrm{KCl,} 2 \mathrm{mmol} / \mathrm{l} \mathrm{MgCl}_{2}, 1 \mathrm{mmol} / \mathrm{l}$ DTT, $0.1 \mathrm{mmol} / \mathrm{l}$ EDTA, $0.1 \mathrm{mmol} / \mathrm{l}$ phenylmethylsulfonylfluoride]. A solution of $80 \mu \mathrm{l}$ of $10 \%$ Nonidet P-40 was added to the homogenates, and the mixture was centrifuged for $2 \mathrm{~min}$ at $14,000 \times g$. The supernatant was collected as a cytosolic fraction for the assays of CD4, CD8, nephrin, podocin, and inhibitory kappa B kinase (ІКB) $\alpha$. The supernatant containing nuclear proteins was collected for nuclear factor kappa B (NF- $\kappa B)$ p65, p38 mitogen-activated protein kinase (p38 MAPK), and phospho (p)-p38 MAPK (Thr180/Tyr182).

Before immunoblotting, and the protein concentration of each tissue was determined using a Bio-Rad protein assay kit (Bio-Rad Laboratories, Japan) and bovine serum albumin as a standard, to ensure equal loading among lanes. Cytosol (70 $\mu \mathrm{g}$ total protein) and nuclear extracts (50 $\mu \mathrm{g}$ total protein) were separated on a $7.5-15 \%$ polyacrilamide gel and electophoretically transferred to nitrocellulose membrane. Membranes were blocked with 5\% nonfat dry milk in Tris-buffered saline Tween $(20 \mathrm{mmol} / \mathrm{l}$ Tris, pH 7.6, $137 \mathrm{mmol} / \mathrm{l} \mathrm{NaCl}$, and $0.1 \%$ Tween 20) for $3 \mathrm{~h}$ at room temperature, followed by an overnight incubation at $4^{\circ} \mathrm{C}$ with with primary antibodies CD4 (Santa Cruz Biotechnology, Inc., Cat. No. sc-7219), CD8 (Santa Cruz Biotechnology, Inc., Cat. No. sc-7188), nephrin (Santa Cruz Biotechnology, Inc., Cat. No. sc-28192), podocin (Santa Cruz Biotechnology, Inc., Cat. No. sc-21009), NFкB p65 (Santa Cruz Biotechnology, Inc., Cat. No. sc-109), IкB $\alpha$ (Cell Signaling Technology, Beverly, MA, USA; Cat. No. 9242), p38 MAPK (Cell Signaling Technology; Cat. No. 9212), p-p38 MAPK (Thr180/Tyr182) (Cell Signaling Technology; Cat. No. 9211), or $\beta$-actin (Santa Cruz
Biotechnology, Inc.; Cat. No. sc-130656). All antibodies were used at a dilution of 1:1000. Three times after washing with Tris-buffered saline Tween 20 (TBST), incubation with appropriate horseradish peroxidase-conjugated secondary antibodies were performed for $1 \mathrm{~h}$ at room temperature. After three additional TBST washes, the immunoreactive bands were visualized by enhanced chemiluminescence (Amersham Biosciences, Buckinghamshire, UK) according to the manufacturer's instructions. Band densities were determined using ATTO Densitograph Software (ATTO Corporation, Tokyo, Japan) and quantified as the ratio to $\beta$-actin. The mean value for samples from the vehicle-treated normal rats on each immunoblot, expressed in densitometry units, was adjusted to a value of 1.0. All experimental sample values were then expressed relative to this adjusted mean value. Tissue sections were sampled from 4 independent experiments.

\section{Statistical analysis}

The results are presented as the mean \pm standard deviation (SD) for each group of animals at the number $(n)$ indicated. Statistical analysis was performed with oneway analysis of variance (ANOVA). The Dunnett range post-hoc comparisons were used to determine the source of significant differences where appropriate. The renal morphohistology and the morphologic analysis for PAS staining were analyzed statistically using the Kruskal-Wallis Test and Dunn's Multiple Comparisons Test. Values of $\mathrm{P}<0.05$ were considered statistically significant.

\section{Results}

\section{Effects on body weight, fasting blood glucose and} glycosylated hemoglobin contents

During 8-week experiment, STZ-diabetic rats were found to have significant weight loss when compared with normal rats (Table 1). The body weight reduction was not obvious in STZ-diabetic rats receiving PSLR during the experimental period (Table 1).

Significant increase in fasting blood glucose in STZdiabetic was observed when compared to normal control group and this change was more marked at the 8th week following diabetes induction. The blood glucose lowering effect was obvious when STZ-diabetic rats were treated with PSLR at the daily dosage of $200 \mathrm{mg} / \mathrm{kg}$ $(20.91 \pm 4.12 \%)$ and $300 \mathrm{mg} / \mathrm{kg}(28.37 \pm 3.92 \%)$ for 8 weeks (Table 1 ). The value of $\mathrm{HbA}_{1 \mathrm{c}}$ was markedly higher in STZ-diabetic rats $(14.31 \pm 1.26 \%)$ when compared with theat from normal rats $(4.79 \pm 1.03 \%$, Table 1$)$. Treatment PSLR at the daily dosage of 200 and $300 \mathrm{mg} / \mathrm{kg}$ for 8 weeks decreased the levels of $\mathrm{HbA}_{1 \mathrm{c}}$ in STZ-diabetic rats by $17.88 \pm 3.29 \%$ and $23.75 \pm 2.86 \%$ relative to the value in STZ-diabetic rats that received vehicle, respectively (Table 1). 
Table 1 Biochemical parameters and the renal levels of cytokines in experimental animals at the end of the eight-week treatment

\begin{tabular}{|c|c|c|c|c|}
\hline & \multirow{2}{*}{$\begin{array}{c}\text { Normal rats } \\
\text { Vehicle }\end{array}$} & \multicolumn{3}{|c|}{ STZ-diabetic rats } \\
\hline & & Vehicle & PSLR 200 & PSLR 300 \\
\hline Body weight (BW) (g/rat) & $370.39 \pm 13.58^{d}$ & $240.99 \pm 16.24^{b}$ & $264.25 \pm 15.11^{\mathrm{b}, \mathrm{c}}$ & $307.72 \pm 14.72^{a, c}$ \\
\hline Kidney weight (KW) (g) & $1.29 \pm 0.23^{c}$ & $2.43 \pm 0.17^{a}$ & $1.85 \pm 0.24^{\mathrm{a}}$ & $1.52 \pm 0.16$ \\
\hline $\mathrm{KW} / \mathrm{BW}$ ratio $\times 1000$ & $3.48 \pm 0.19^{d}$ & $10.08 \pm 0.17^{b}$ & $7.00 \pm 0.12^{\mathrm{b}, \mathrm{c}}$ & $4.94 \pm 0.11^{\mathrm{b}, \mathrm{c}}$ \\
\hline Plasma glucose (mg/dl) & $92.68 \pm 8.59^{d}$ & $425.73 \pm 18.07^{b}$ & $336.25 \pm 14.92^{\mathrm{b}, \mathrm{c}}$ & $306.92 \pm 15.31^{b, c}$ \\
\hline HbAlc (\%) & $4.79 \pm 1.03^{d}$ & $14.31 \pm 1.26^{b}$ & $11.75 \pm 1.18^{\mathrm{b}}$ & $10.91 \pm 1.21^{b}$ \\
\hline Urine volume (ml/day) & $9.26 \pm 2.43^{d}$ & $28.16 \pm 9.13^{b}$ & $18.21 \pm 6.28^{b, c}$ & $15.84 \pm 7.31^{\mathrm{b}, \mathrm{c}}$ \\
\hline Urine protein (mg/day) & $6.95 \pm 2.84^{d}$ & $34.83 \pm 5.29^{b}$ & $16.41 \pm 4.13^{\mathrm{a}, \mathrm{c}}$ & $12.27 \pm 5.21^{d}$ \\
\hline Plasma $\mathrm{Cr}(\mu \mathrm{mol} / \mathrm{l})$ & $38.50 \pm 6.34^{d}$ & $96.29 \pm 8.73^{b}$ & $84.10 \pm 8.31^{b}$ & $67.92 \pm 7.32^{\mathrm{b}, \mathrm{c}}$ \\
\hline BUN (mmol/l) & $7.21 \pm 1.58^{c}$ & $16.29 \pm 2.80^{\mathrm{a}}$ & $13.16 \pm 2.11^{\mathrm{a}}$ & $11.45 \pm 2.21^{\mathrm{a}, \mathrm{c}}$ \\
\hline $\operatorname{Ccr}(\mathrm{ml} / \mathrm{min})$ & $3.88 \pm 0.89^{d}$ & $1.65 \pm 0.54^{b}$ & $2.37 \pm 0.68^{\mathrm{a}, \mathrm{c}}$ & $2.77 \pm 0.34^{d}$ \\
\hline Plasma AST (U/I) & $125.85 \pm 10.47^{d}$ & $374.68 \pm 17.34^{b}$ & $219.88 \pm 18.26^{\mathrm{b}, \mathrm{c}}$ & $159.57 \pm 17.53^{d}$ \\
\hline Plasma ALT (U/l) & $57.67 \pm 7.92^{d}$ & $218.67 \pm 17.12^{b}$ & $145.14 \pm 15.78^{\mathrm{b}, \mathrm{c}}$ & $103.42 \pm 13.24^{\mathrm{a}, \mathrm{d}}$ \\
\hline Renal IL-6 (pg/mg protein) & $54.06 \pm 8.46^{d}$ & $159.34 \pm 11.38^{\mathrm{b}}$ & $126.34 \pm 10.28^{b, c}$ & $105.89 \pm 10.94^{\mathrm{b}, \mathrm{c}}$ \\
\hline Renal TNF-a (pg/mg protein) & $69.19 \pm 9.34^{d}$ & $172.91 \pm 10.11^{\mathrm{b}}$ & $137.12 \pm 9.13^{\mathrm{b}, \mathrm{c}}$ & $109.45 \pm 7.51^{b, c}$ \\
\hline Renal IL-10 (pg/mg protein) & $64.77 \pm 4.17^{d}$ & $28.43 \pm 4.25^{b}$ & $36.49 \pm 3.91^{b, c}$ & $44.64 \pm 3.77^{\mathrm{b}, \mathrm{c}}$ \\
\hline
\end{tabular}

STZ-diabetic rats were dosed by oral gavage once per day for eight weeks with $200 \mathrm{mg} / \mathrm{kg} / \mathrm{day}$ PSLR (PSLR 200), $300 \mathrm{mg} / \mathrm{kg} /$ day PSLR (PSLR 300). Normal or STZ-diabetic rats receiving vehicle treatment were given the same volume of vehicle (distilled water) used to disperse PSLR. Values (mean \pm SD) were obtained for each group of 8 animals. ${ }^{a} \mathrm{P}<0.05$ and ${ }^{\mathrm{b}} \mathrm{P}<0.01$ compared to the values of vehicle-treated normal rats, respectively. ${ }^{\mathrm{C}} \mathrm{P}<0.05$ and ${ }^{\mathrm{d}} \mathrm{P}<0.01$ compared to the values of vehicle-treated STZ-diabetic rats, respectively.

Effects on renal and hepatic function related parameters STZ-diabetic rats showed an increase in $24 \mathrm{~h}$ urine volume, accompanied by increase in urine protein excretion (Table 1). After 8 weeks of $300 \mathrm{mg} / \mathrm{kg} /$ day PSLR treatment, $24 \mathrm{~h}$ urine volume and $24 \mathrm{~h}$ urine protein excretion of STZ-diabetic rats were markedly less than their vehicle-treated counterparts (Table 1). The levels of Scr and BUN in STZ-diabetic rats were obviously higher than normal control group. There was an effective reduction in the levels of Scr and BUN in STZ-diabetic rats receiving 8 weeks of PSLR treatment when compared with their vehicle-counterparts (Table 1). In addition, increased Ccr in STZ-diabetic rats was observed after 8 weeks of PSLR treatment (Table 1).

Plasma ALT and AST activities in the diabetic control group were significantly higher than those in the normal control group (Table 1). The ALT and AST activities were markedly reduced in STZ-diabetic rats treated for eight weeks with PSLR (Table 1).

\section{Influences on the kidney hypertrophy}

The mean weight of the left kidney and the ratio of kidney weight to body weight in vehicle-treated STZ-diabetic rats were increased significantly compared with those in the normal group. Treatment of STZ-diabetic rats with $200 \mathrm{mg} / \mathrm{kg} /$ day PSLR slightly reduced the degree of renal hypertrophy (Table 1). Kidney hypertrophy and the ratio of kidney weight to body weight were markedly reduced in STZ-diabetic rats treated for eight weeks with $300 \mathrm{mg} / \mathrm{kg} /$ day PSLR (Table 1).

\section{Influences on the renal cytokines}

Renal concentrations of inflammatory cytokines TNF- $\alpha$ and IL- 6 of STZ-diabetic rats were significantly higher compared to their vehicle-treated controls (Table 1). PSLR treatments reduced renal IL- 6 and TNF- $\alpha$ levels in a dose-dependent manner (Table 1).

The renal IL-10 level of STZ-diabetic rats was significantly lower than that in the normal control (Table 1). The decreased renal IL-10 level in the kidneys of STZdiabetic rats was enhanced dose-dependently by PSLR treatment (Table 1).

\section{Influences on the renal histology}

The changes in renal histology of the different groups are shown in Figure 1A. The sections from the normal control group were normal sizes without any abnormal phenomena by visual observation (Figure 1A). Conversely, glomerular proliferation and mesangial matrix augmentation occurred in the diabetic group. These broad changes caused loading of the Bowman's capsule space and adhesion of capillaries to the wall (Figure 1A). The structures of the kidney sections of PSLR (300 mg/kg/day)-treated groups also changed in morphology, however, a decreased extent of the expansions in the glomerulus and the mesangial matrix were observed (Figure 1A). 


\section{(A)}

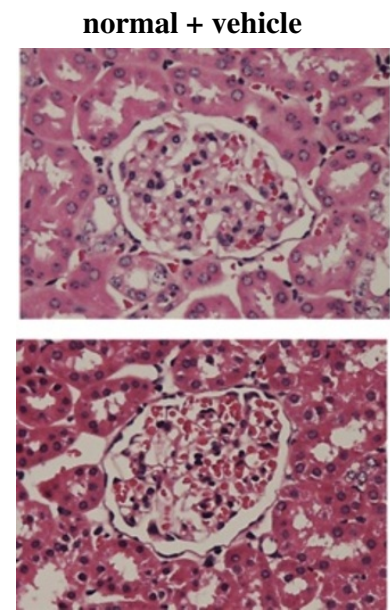

STZ + PSLR 200
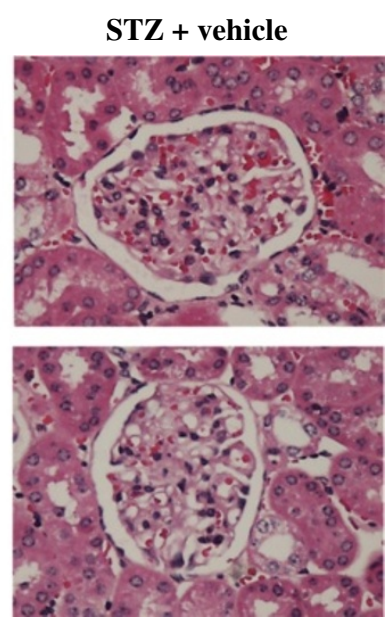

STZ + PSLR 300
(B)

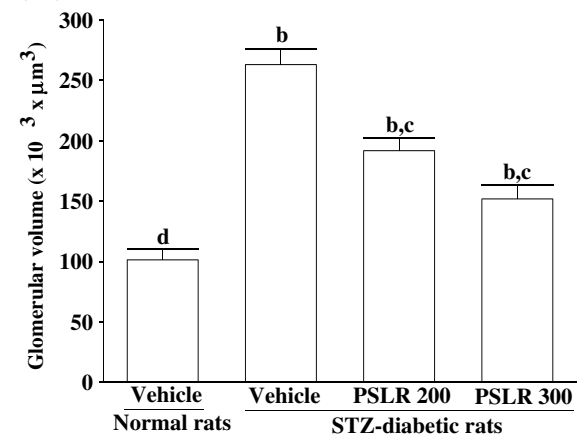

(C)

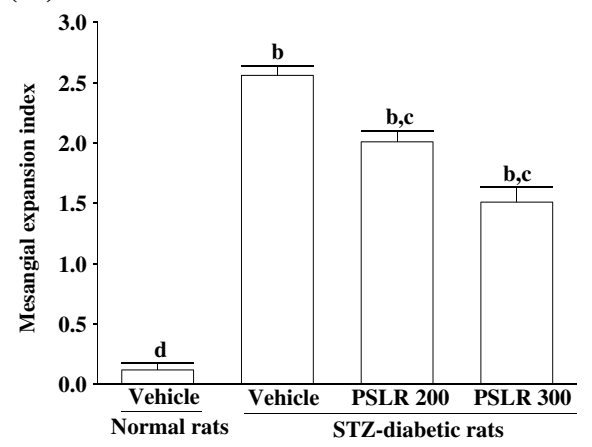

Figure 1 Effects of treatments on the renal histology. (A) Representative photomicrographs (original magnification, 400X) of H\&E-stained kidney sections, (B) glomerular volume, and (C) expansion of matrix index expressed as a quantitative estimate score in experimental groups. STZ-diabetic rats were dosed by oral gavage once per day for eight weeks with $200 \mathrm{mg} / \mathrm{kg}$ PSLR (STZ + PSLR 200) or $300 \mathrm{mg} / \mathrm{kg}$ PSLR (STZ + PSLR 300). Normal or STZ-diabetic rats receiving vehicle treatment were given the same volume of vehicle (distilled water) used to to disperse PSLR. Values (mean \pm SD) were obtained for each group of 4 animals. ${ }^{b} P<0.01$ compared to the values of vehicle-treated normal rats (normal + vehicle). ${ }^{c} P<0.05$ and ${ }^{d} P<0.01$ compared to the values of vehicle-treated STZ-diabetic rats (STZ + vehicle), respectively.

When a semiquantitative analysis was used, it became readily apparent that a difference in the histological change was present the diabetic control group and other groups. The glomerular volume and the extent of mesangial matrix nearly increased to 2.61 - and 2.56-fold in diabetic control group compared with the normal control group, respectively (Figure $1 \mathrm{~B}$ and $\mathrm{C}$ ). The glomerular volume and the extent of mesangial matrix in PSLR (300 mg/kg/day)-treated STZ-diabetic rats were decreased $42.58 \pm 5.62$ and $41.01 \pm 6.25 \%$, respectively, relative to those in diabetic control group (Figure 1B and C).

\section{Effects on macrophage infiltration}

Kidneys from control rats did not show any significant macrophage infiltration; however, STZ-diabetic rats demonstrated prominent macrophage (ED-1-positive cells) infiltration in the glomerulus (Figure 2). Treatment of
STZ-diabetic rats with $300 \mathrm{mg} / \mathrm{kg} /$ day PSLR for eight weeks caused a $42.76 \pm 6.22 \%$ reduction of macrophage influx relative to that in their vehicle-treated counterparts (Figure 2).

\section{Effects on renal T cells expression}

Renal CD4+ cells protein expression was 3.1-fold higher in STZ-diabetic rats compared with normal control, and $300 \mathrm{mg} / \mathrm{kg} /$ day PSLR treatment attenuated this increase by $64.28 \pm 5.71 \%$ (Figure 3A). The STZ-induced upregulation of renal CD8 + T cells was reduced $53.01 \pm 5.34 \%$ relative to that in vehicle-treated STZ-diabetic rats after eight weeks of treatment with $300 \mathrm{mg} / \mathrm{kg} /$ day PSLR (Figure 3B).

\section{Changes in protein expressions of nephrin and podocin}

Western blot assay indicated that the renal nephrin and podocin proteins were less expressed in vehicle-treated STZ-diabetic rats (Figure 4). Eight weeks of PSLR 
$(300 \mathrm{mg} / \mathrm{kg} /$ day) treatment resulted in a marked increase of renal nephrin and podocin protein expression in STZ-diabetic rats (Figure 4).

\section{Influences on the renal expression of NF-кB and ІкBa}

As shown in Figure 5A, the cytosolic ІкB $\alpha$ in the kidney of STZ-diabetic rats was lower than that in the normal group, and $300 \mathrm{mg} / \mathrm{kg} /$ day PSLR treatment reduced IKB $\alpha$ degradation. The accumulation of NF- $\mathrm{KB}$ proteins in the nucleus of glomeruli from vehicle-treated STZ-diabetic rats relative to normal group were observed in Figure 5B. The increased expression of NF- $\mathrm{kB}$ protein found in the nucleus of kidneys from STZ-diabetic rats was reduced after 8-week of $300 \mathrm{mg} / \mathrm{kg} /$ day PSLR treatment (Figure 5B).

\section{Effects on the protein expression and phosphorylation of} p38 MAPK

The immunoblot results showed that the protein levels and phosphorylation degree of p38 MAPK were 1.81 and 2.93 fold higher in kidney of STZ-diabetic rats as compared to the normal group (Figure 6). The STZ also significantly increased the p-p38 MAPK/p38 MAPK ratio (by 1.62 fold relative to those in vehicle-treated normal rats) in kidney of the rats (Figure 6). These STZ-

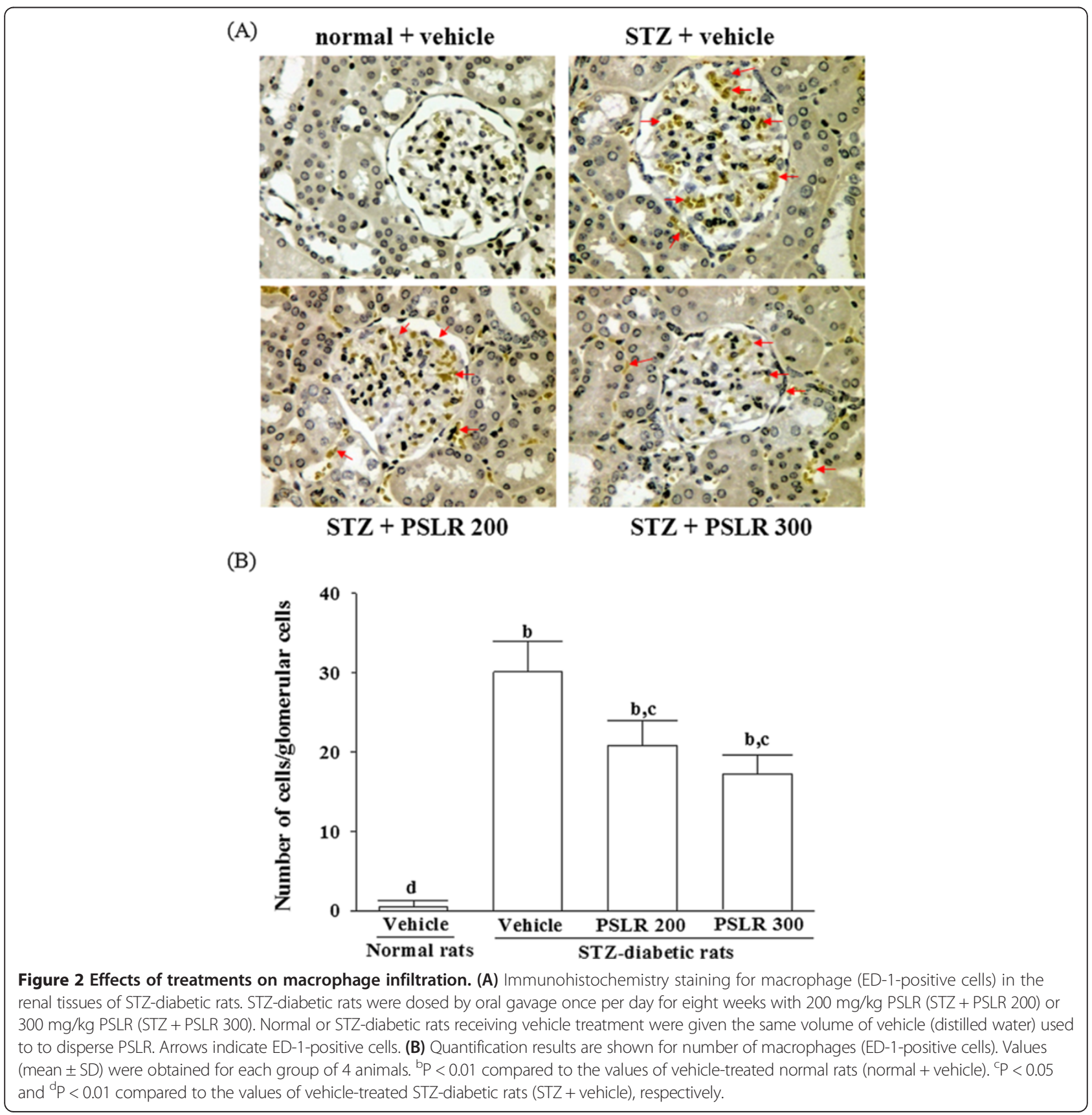




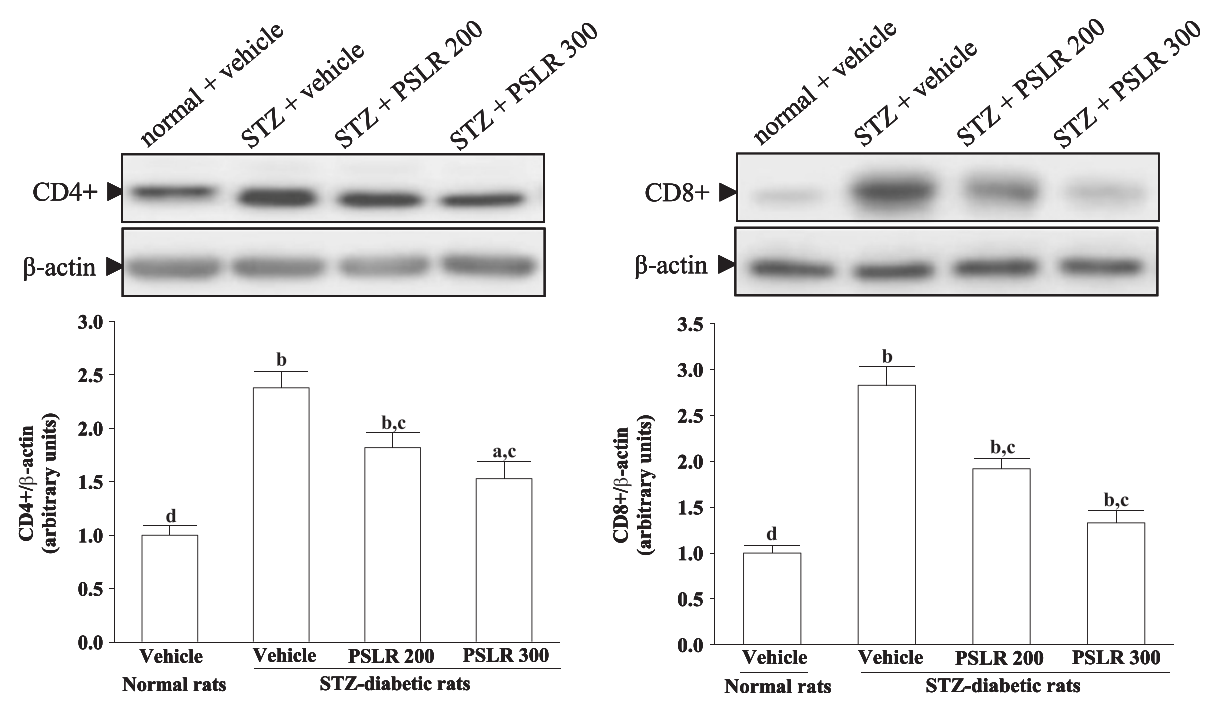

Figure 3 Effects of treatments on protein expressions of CD4+ and CD8+ T cells in the renal tissues of STZ-diabetic rats. STZ-diabetic rats were dosed by oral gavage once per day for eight weeks with $200 \mathrm{mg} / \mathrm{kg}$ PSLR (STZ + PSLR 200) or $300 \mathrm{mg} / \mathrm{kg}$ PSLR (STZ + PSLR 300). Normal or STZ-diabetic rats receiving vehicle treatment were given the same volume of vehicle (distilled water) used to to disperse PSLR. Values (mean \pm SD) were obtained for each group of 4 animals. ${ }^{a} \mathrm{P}<0.05$ and ${ }^{\mathrm{b}} \mathrm{P}<0.01$ compared to the values of vehicle-treated normal rats (normal + vehicle), respectively. ${ }^{c} \mathrm{P}<0.05$ and ${ }^{d} \mathrm{P}<0.01$ compared to the values of vehicle-treated STZ-diabetic rats (STZ + vehicle), respectively.

induced up-regulations in protein levels and phosphorylation degree of p38 MAPK were reversed in the kidney after 8 -week treatment with $300 \mathrm{mg} / \mathrm{kg} /$ day PSLR by $31.05 \pm 5.81$ and $27.86 \pm 6.24 \%$ decreases relative to those in vehicle-treated STZ-diabetic rats (Figure 6). The ratio of p-p38 MAPK/p38 MAPK were reversed in the kidney after 8-week treatment with $300 \mathrm{mg} / \mathrm{kg} /$ day PSLR by $43.12 \pm 3.25 \%$ decreases relative to those in vehicle-treated STZ-diabetic rats (Figure 6).

\section{Discussion}

In the present study, untreated STZ-diabetic rats developed severe hyperglycemia with polyuria as a result of osmotic diuresis. It is widely known that hyperglycemia can induce microalbuminuria by a hyperfiltration mechanism [19]. We found that the 8 week PSLR (300 mg/kg/day) administration regimen significantly inhibited the glycosylation of hemoglobin by lowering hyperglycemia in STZ-diabetic rats. The STZ-diabetic rats treated with PSLR showed an impressive decrease in the amount of proteinuria in parallel with the decrease in urinary volume, probably as a result of the amelioration of hyperglycemia as shown in other studies $[7,8]$.

As the final and major size barrier to the passage of proteins and other macromolecules, slit diaphragm, the key structure of foot process, plays a crucial role in the occurrence and development of proteinuria [20]. Nephrin, a transmembrane protein belonging to the immunoglobulin superfamily of cell adhesion molecules, was the first identified structural protein of the podocyte slit diaphragm which has dramatic functional importance [21]. Attenuation of nephrin expression in experimental kidney diseases is associated with a loss of the slit diaphragm and massive proteinuria [21]. Podocin, a stomatin family member, is another important component of the glomerular slit diaphragm complex which colocalizes and interacts with cytosolic tail of nephrin in the lipid rafts of the podocyte foot process cell membrane [22]. Mutations in the podocin gene cause severe structural podocyte alterations and massive proteinuria leading to nephrotic syndrome [22]. It has been demonstrated that reduction of podocin leads to decreased expression and obvious redistribution of nephrin [23]. We thus examined whether antiproteinuric effects of PSLR correlated with alterations in the abundance of nephrin and podocin. Our observations demonstrated that rats with diabetes lost their functional podocin, exhibited less nephrin protein expressions, and developed proteinuria. This down regulated expression of renal nephrin and podocin protein was alleviated in the 8 weeks treatment with PSLR. In addition, PSLR treatment ameliorated proteinuria and glomerular pathological changes in diabetic kidney. We concededly demonstrated that the renal protective effect of PSLR might be related with the upregulation on nephrin and podocin expressions in the glomeruli from diabetic rats.

It is known that among inflammatory cytokines, such as TNF- $\alpha$ and IL- 6 are relevant to the development of diabetic nephropathy, with diverse actions potentially involved in the development of complications [24]. Thus, the suppression on IL- 6 and TNF- $\alpha$ could retard or 

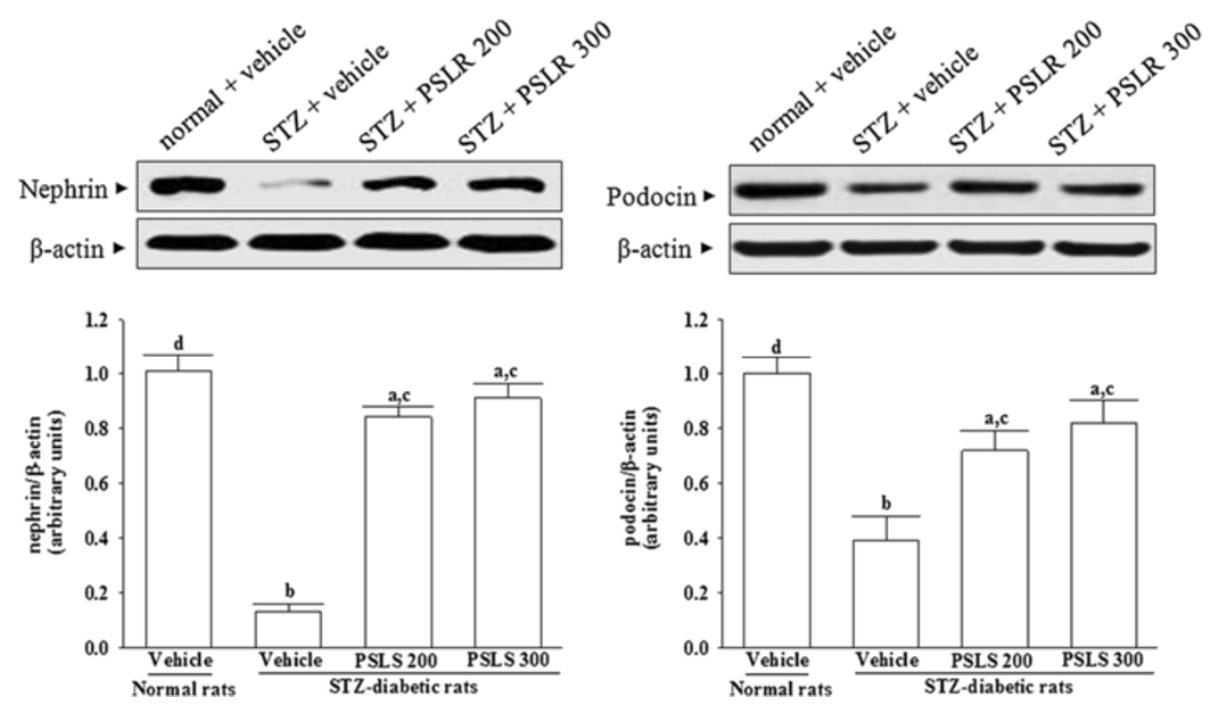

Figure 4 Effects of treatments on protein expressions of nephrin and podocin in the renal tissues of STZ-diabetic rats. STZ-diabetic rats were dosed by oral gavage once per day for eight weeks with $200 \mathrm{mg} / \mathrm{kg}$ PSLR (STZ + PSLR 200) or $300 \mathrm{mg} / \mathrm{kg}$ PSLR (STZ + PSLR 300). Normal or STZ-diabetic rats receiving vehicle treatment were given the same volume of vehicle (distilled water) used to to disperse PSLR. Values (mean \pm SD) were obtained for each group of 4 animals. ${ }^{\mathrm{a}} \mathrm{P}<0.05$ and ${ }^{\mathrm{b}} \mathrm{P}<0.01$ compared to the values of vehicle-treated normal rats (normal + vehicle), respectively. ${ }^{c} \mathrm{P}<0.05$ and ${ }^{\mathrm{d}} \mathrm{P}<0.01$ compared to the values of vehicle-treated STZ-diabetic rats (STZ + vehicle), respectively.

alleviate inflammation and improve nephropathy. Our study found that the dietary intake PSLR could effectively decrease renal IL-6 and TNF- $\alpha$ levels in diabetic rats. These results similar with the effects of metformin to protect against DN by modulation of pro-inflammatory gene expression levels [25]. Antiinflammatory and immunosuppressive cytokines such as IL-10, could downregulate the production of proinflammatory cytokines from monocytes
[26]. The elevation of IL-10 from PSLR supplement as observed in our present study might contribute to alleviate renal inflammatory stress. Therefore, our present study suggested that PSLR could alleviate diabetic renal inflammation via suppressing the release of IL- 6 and TNF- $\alpha$ release, and increasing renal IL-10 levels.

$\mathrm{T}$ lymphocytes are known to interact with macrophages and regulate the inflammatory cascade [27].
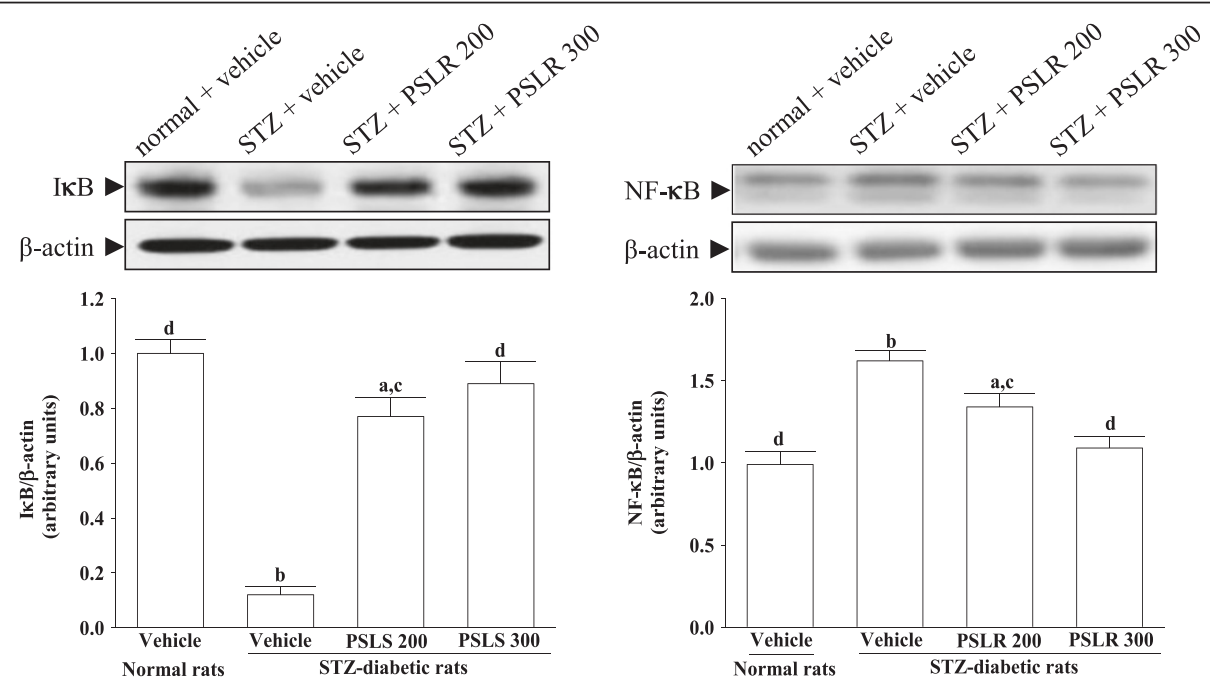

Figure 5 Effects of treatments on protein expressions of renal IKB and NF-KB in the renal tissues of STZ-diabetic rats. STZ-diabetic rats were dosed by oral gavage once per day for eight weeks with $200 \mathrm{mg} / \mathrm{kg}$ PSLR (STZ + PSLR 200) or $300 \mathrm{mg} / \mathrm{kg}$ PSLR (STZ + PSLR 300). Normal or STZ-diabetic rats receiving vehicle treatment were given the same volume of vehicle (distilled water) used to to disperse PSLR. Values (mean \pm SD) were obtained for each group of 4 animals. ${ }^{\mathrm{a}} \mathrm{P}<0.05$ and ${ }^{\mathrm{b}} \mathrm{P}<0.01$ compared to the values of vehicle-treated normal rats (normal + vehicle), respectively. ${ }^{\mathrm{c}} \mathrm{P}<0.05$ and ${ }^{\mathrm{d}} \mathrm{P}<0.01$ compared to the values of vehicle-treated STZ-diabetic rats (STZ + vehicle), respectively. 


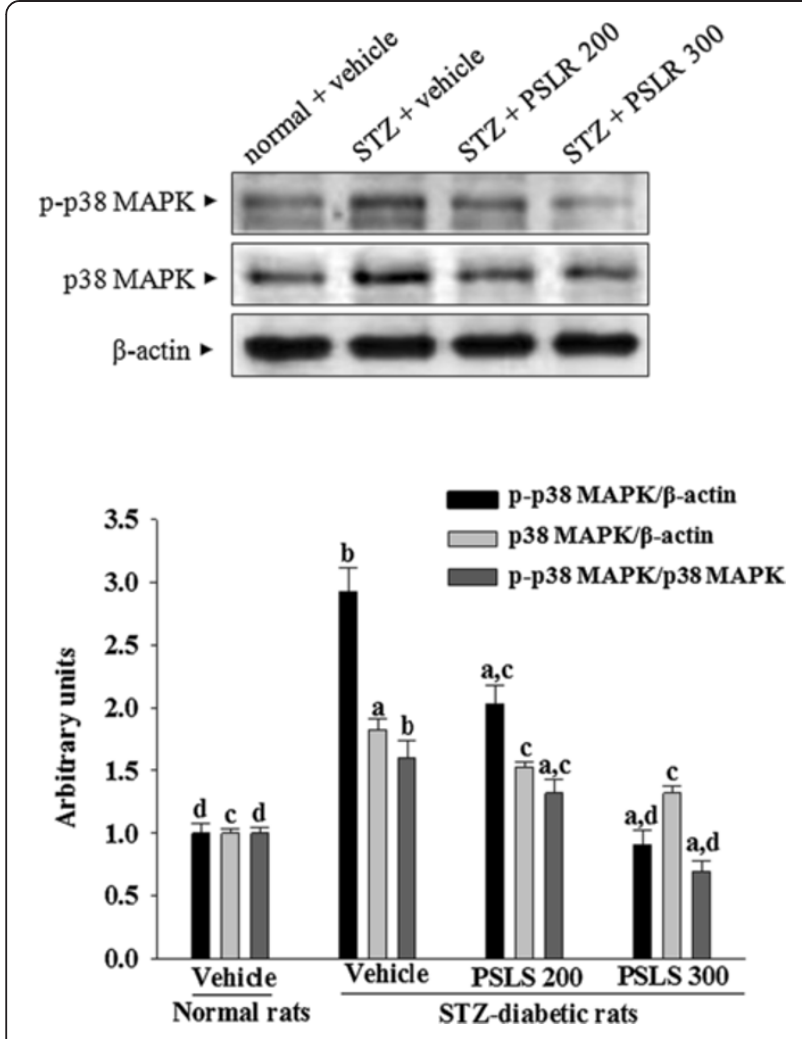

Figure 6 Effects of treatments on protein expression and phosphorylation of $p$-38 MAPK in the renal tissues of STZ-diabetic rats. STZ-diabetic rats were dosed by oral gavage once per day for eight weeks with $200 \mathrm{mg} / \mathrm{kg}$ PSLR (STZ + PSLR 200) or $300 \mathrm{mg} / \mathrm{kg}$ PSLR (STZ + PSLR 300). Normal or STZ-diabetic rats receiving vehicle treatment were given the same volume of vehicle (distilled water) used to to disperse PSLR. Ratios of p-p38 MAPK/ $\beta$-actin, p38 MAPK $\beta$-actin, or p-p38 MAPK/p38 MAPK are expressed as the mean with $S D$ ( $n=4$ per group) in each column. ${ }^{a} P<0.05$ and ${ }^{b} P<0.01$ compared to the values of vehicle-treated normal rats (normal + vehicle), respectively. ${ }^{c} P<0.05$ and ${ }^{d} P<0.01$ compared to the values of vehicle-treated STZ-diabetic rats (STZ + vehicle), respectively.

Increased infiltration of monocytes/macrophages and activated $\mathrm{T}$ lymphocytes, as well as augmented expression of inflammatory cytokines in the kidneys have been found in patients with DN [28]. Using accumulation of ED-1 as a marker of macrophage activation, we have demonstrated increased activation of macrophage in the glomeruli of kidney tissue from diabetic animals. The suppressive effect from PSLR on the expression of ED-1 was observed. Western blot analyses revealed increased expression of CD4+, CD8 + T cells in diabetic kidneys were also allivated by PSLR supplement. Therefore, the possible mechanism of preventing the renal disease progression may be due to the effect of PSLR on attenuating inflammation through reducing macrophage and $\mathrm{T}$ cells infiltration in DN.

Studies have also demonstrated that NF- $\mathrm{kB}$ was involved in the induction of monocyte chemotactic protein-1 in mesangial cell cultured under high glucose condition and subsequently mediated macrophage accumulation [29]. $\mathrm{NF}-\mathrm{kB}$ is present in the cytoplasma complexed to its inhibitory protein known as I $\mathrm{B}$. After activation by a number of physiological and nonphysiological stimuli, I $\mathrm{B}$ dissociates from NF- $\mathrm{kB}$ within minutes and undergoes ubiquitination and degradation. Once NF- $k B$ is released from the inhibitory unit IкB, the NF-кB is then translocated into the nucleus. Upon its nuclear translocation, NF- $\mathrm{kB}$ undergoes phosphorylation on serine 276 in its p65 subunit and associates with surrounding chromatin components. It subsequently binds with DNA and promotes the transcription of proinflammatory cytokines [30]. After PSLR treatment for 8 weeks, the nucleus protein levels of NF-kB p65 were significantly inhibited, implying the effect of PSLR on diabetic rats with renal injury may result from the inhibition of NF-kB activation. And in diabetic kidney, the cotosolic protein levels of IKB $\alpha$ were decreased, while PSLR treatment could

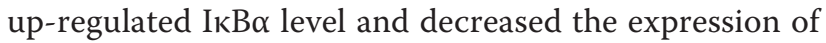
inflammatory cytokines regulated by NF- $\mathrm{BB}$, such as TGF- $\beta 1$, TNF- $\alpha$ and IL-6, which increased in diabetic rats. Treated rats exhibited reduced levels of glucose and HbAc1. It should be noted that the significant influence of PSLR on hyperglycemia in STZ-diabetic rats was observed, supporting the traditional use of Liriopes Radix as a hypoglycemic agent $[7,8]$. We believe that the ability of PSLR to inactivate hyperglycemia-induced activation of NF- $\mathrm{kB}$ and thus inhibited the macrophages infiltration is its likely another mechanisms of action.

Accumulating evidence also suggested the development of DN was associated with the activation of several stress-sensitive signal pathways, including MAPK cascades. p38 MAPK followed by the activation of NF- $\mathrm{kB}$ participates in the intracellular signal transduction and production of cytokines and chemokines [31]. p38 MAPK was activated in vivo in glomeruli from diabetic rats and in vitro in mesangial cells exposed to high glucose [32]. Increased renal cortical p38 MAPK activity in diabetic rats could be attenuated by improved glycemic control [33]. Treatment with PSLR also reduced the elevated levels of p38 MAPK in the kidneys of STZ-diabetic rats, suggesting that the renal protective effect of PSLR might be also related with the modulation of p38 MAPK signal transduction to attenuate diabetes-affected renal dysfunction. We thus concluded that attainment of good glycemic control by PSLR treatment could abrogate the increased renal p38 MAPK pathway activation in diabetic rats and led to minimize risk of DN. This finding may support the protective role of p38 MAPK and NF- $\mathrm{kB}$ signaling pathways inhibition in the reduction of the development of DN. Taken together, all the above results suggest that the beneficial effect of PSLR in rats with $\mathrm{DN}$ is at least in part through antihyperglycemia which 
was accompanied by inhibition of macrophage infiltration via reducing NF- $\mathrm{kB}$ and $\mathrm{p} 38$ MAPK mediated inflammatory response. However, further pharmacological evaluations are required to isolate and identify the active principles in the plant as well as elucidating their mechanisms of action.

Toxicity studies on many herbal preparations have not been conducted. Although it is generally assumed that herbal preparations have fewer side effects than modern medicines; care should be taken with the chronic consumption of large doses of traditional remedies. ALT and AST are two of the most reliable markers of hepatocellular injury or necrosis [34]. We found that rats treated with PSLR exhibited no evidence of hepatotoxicity. Thus, PSLR could be considered with a margin of safety for oral use. Since toxicity in humans cannot always be entirely extrapolated from animal studies, clinical evaluation should be performed to precisely define the safe dosage to advice in humans.

\section{Conclusions}

These results demonstrate that the renal protective effects of PSLR occur through improved glycemic control and renal structural changes, which are involved in the inhibition of NF- $\mathrm{kB}$ and p38 MAPK mediated inflammation. Given these promising preclinical findings, we believe that PSLR might be considered as potential adjuvant entity for DN treatment.

\section{Competing interests}

The authors declare that they have no competing interests.

\section{Authors' contributions}

HJL carried out the experimentation as part of PhD study. MCW contributed to study design, data interpretation and manuscript writing. TTF and SDL performed the experiments and analysis and participated to data interpretation. SLL supervised the work and evaluated the data. IML supervised the work, evaluated the data, manuscript writing and corrected the manuscript for publication. All authors read and approved the final manuscript.

\section{Authors' information}

Ming-Chang Wu is the co-correspondence.

\section{Acknowledgements}

The present study was supported by a grant from the National Science Council Grant (Grant No: NSC102-2320-B-127-001-MY3) of Taiwan, the Republic of China.

Received: 26 January 2014 Accepted: 30 April 2014

Published: 13 May 2014

\section{References}

1. Bascones-Martinez A, Matesanz-Perez P, Escribano-Bermejo M, González-Moles MÁ, Bascones-llundain J, Meurman JH: Periodontal disease and diabetesReview of the Literature. Med Oral Patol Oral Cir Bucal 2011, 16:e722-e729.

2. Ruan X, Guan Y: Metabolic syndrome and chronic kidney disease. J Diabetes 2009, 1:236-245.

3. Nguyen D, Ping F, Mu W, Hill P, Atkins RC, Chadban SJ: Macrophage accumulation in human progressive diabetic nephropathy. Nephrology 2006, 11:226-231.

4. Sakai N, Wada T, Furuichi K, Iwata Y, Yoshimoto K, Kitagawa K, Kokubo S, Kobayashi M, Takeda S, Kida H, Kobayashi K, Mukaida N, Matsushima K,
Yokoyama H: p38 MAPK phosphorylation and NF-kappa B activation in human crescentic glomerulonephritis. Nephrol Dial Transplant 2002, 17:998-1004.

5. Wais M, Nazish I, Samad A, Beg S, Abusufyan S, Ajaj SA, Aqil M: Herbal drugs for diabetic treatment: an updated review of patents. Recent Pat Antiinfect Drug Discov 2012, 7:53-59.

6. Liu W, Wang ZL, Liang HQ: Studies on the chemical constituents of Liriope spicata Lour (Thunb), var. prolifera Y.T. Ma. Acta Pharm Sin 1989, 24:749-754

7. Chen X, Bai X, Liu Y, Tian L, Zhou J, Zhou Q, Fang J, Chen J: Anti-diabetic effects of water extract and crude polysaccharides from tuberous root of Liriope spicata var. prolifera in mice. J Ethnopharmacol 2009, 122:205-209.

8. Bai X, Chen X, Liu Y, Tian L, Zhou Q, Liu S, Fang J, Chen J: Effects of water extract and crude polysaccharides from Liriope spicata var. prolifera on InsR/IRS-1/PI3K pathway and glucose metabolism in mice. J Ethnopharmacol 2009, 125:482-486

9. Xiao ZQ, Wang YL, Yue YD, Zhang YT, Chen CP, Wan LS, Deng B, Liu ZX, Chen JC: Preventive effects of polysaccharides from Liriope spicata var. prolifera on diabetic nephropathy in rats. Int J Biol Macromol 2013, 61:114-120.

10. Hu ZF, Chen LL, Qi J, Wang YH, Zhang H, Yu BY: Two new benzofuran derivatives with anti-inflammatory activity from Liriope spicata var. prolifera. Fitoterapia 2011, 82:190-192.

11. Dronavalli S, Duka I, Bakris GL: The pathogenesis of diabetic nephropathy. Nat Clin Pract Endocrinol Metab 2008, 4:444-452.

12. Yemm EW, Willis AJ: The estimation of carbohydrates in plant extracts by anthrone. Biochem J 1954, 57:508-514.

13. Bagheri F, Gol A, Dabiri S, Javadi A: Preventive effect of garlic juice on renal reperfusion injury. Iran J Kidney Dis 2011, 5:194-200.

14. Yin MC, Hsu CC, Chiang PF, Wu WJ: Antiinflammatory and antifibrogenic effects of s-ethyl cysteine and s-methyl cysteine in the kidney of diabetic mice. Mol Nutr Food Res 2007, 51:572-579.

15. Lowry OH, Rosebrough NJ, Farr AL: Protein measurement with the Folin phenol reagent. J Biol Chem 1951, 193:265-275.

16. Kanetsuna Y, Hirano K, Nagata M, Gannon MA, Takahashi K, Harris RC, Breyer MD, Takahashi T: Characterization of diabetic nephropathy in a transgenic model of hypoinsulinemic diabetes. Am J Physiol Renal Physiol 2006, 291:F1315-F1322.

17. Liu IM, Tzeng TF, Liou SS, Chang CJ: The amelioration of streptozotocin diabetes-induced renal damage by Wu-Ling-San (Hoelen Five Herb Formula), a traditional Chinese prescription. J Ethnopharmacol 2009, 124:211-218.

18. Ghosh SS, Massey HD, Krieg R, Fazelbhoy ZA, Ghosh S, Sica DA, Fakhry I, Gehr TW: Curcumin ameliorates renal failure in 5/6 nephrectomized rats: role of inflammation. Am J Physiol Renal Physiol 2009, 296:F1146-F1157.

19. Najafian B, Alpers CE, Fogo AB: Pathology of human diabetic nephropathy. Contrib Nephrol 2011, 170:36-47.

20. Kawachi H, Miyauchi N, Suzuki K, Han GD, Orikasa M, Shimizu F: Role of podocyte slit diaphragm as a filtration barrier. Nephrology 2006, 11:274-281.

21. Welsh Gl, Saleem MA: Nephrin-signature molecule of the glomerular podocyte? J Pathol 2010, 220:328-337.

22. Piscione TD, Licht C: Genetics of proteinuria: an overview of gene mutations associated with nonsyndromic proteinuric glomerulopathies. Adv Chronic Kidney Dis 2011, 18:273-289.

23. Fan Q, Ding J, Zhang J, Guan N, Deng J: Effect of the knockdown of podocin mRNA on nephrin and alpha-actinin in mouse podocyte. Exp Biol Med (Maywood) 2004, 229:964-970.

24. Navarro-González JF, Mora-Fernández C: The role of inflammatory cytokines in diabetic nephropathy. J Am Soc Nephrol 2008, 19:433-442.

25. Sabat R, Grütz G, Warszawska K, Kirsch S, Witte E, Wolk K, Geginat J: Biology of interleukin-10. Cytokine Growth Factor Rev 2010, 21:331-344.

26. Chen S, Jim B, Ziyadeh FN: Diabetic nephropathy and transforming growth factor-beta: transforming our view of glomerulosclerosis and fibrosis build-up. Semin Nephrol 2003, 23:532-543.

27. Monney L, Sabatos CA, Gaglia JL, Ryu A, Waldner H, Chernova T, Manning S, Greenfield EA, Coyle AJ, Sobel RA, Freeman GJ, Kuchroo VK: Th1-specific cell surface protein Tim-3 regulates macrophage activation and severity of an autoimmune disease. Nature 2002, 415:536-541.

28. Eller K, Kirsch A, Wolf AM, Sopper S, Tagwerker A, Stanzl U, Wolf D, Patsch $W$, Rosenkranz AR, Eller P: Potential role of regulatory $T$ cells in reversing 
obesity-linked insulin resistance and diabetic nephropathy. Diabetes 2011, 60:2954-2962.

29. Lee FT, Cao Z, Long DM, Panagiotopoulos S, Jerums G, Cooper ME, Forbes JM: Interactions between angiotensin II and NF-kappaB-dependent pathways in modulating macrophage infiltration in experimental diabetic nephropathy. J Am Soc Nephrol 2004, 15:2139-2151.

30. Okazaki T, Sakon S, Sasazuki T, Sakurai H, Doi T, Yagita H, Okumura K, Nakano H: Phosphorylation of serine 276 is essential for p65 NF-kappaB subunit-dependent cellular responses. Biochem Biophys Res Commun 2003, 300:807-812.

31. Sakai N, Wada T, Furuichi K, Iwata Y, Yoshimoto K, Kitagawa K, Kokubo S, Kobayashi M, Hara A, Yamahana J, Okumura T, Takasawa K, Takeda S, Yoshimura M, Kida H, Yokoyama H: Involvement of extracellular signal-regulated kinase and p38 in human diabetic nephropathy. Am J Kidney Dis 2005, 45:54-65.

32. Lv ZM, Wang Q, Wan $\mathrm{Q}$, Lin JG, Hu MS, Liu YX, Wang R: The role of the p38 MAPK signaling pathway in high glucose-induced epithelial-mesenchymal transition of cultured human renal tubular epithelial cells. PLOS One 2011, 6:e22806.

33. Komers R, Lindsley JN, Oyama TT, Cohen DM, Anderson S: Renal p38 MAP kinase activity in experimental diabetes. Lab Invest 2007, 87:548-558.

34. Giboney PT: Mildly elevated liver transaminase levels in the asymptomatic patient. Am Fam Physician 2005, 71:1105-1110.

doi:10.1186/1472-6882-14-156

Cite this article as: Lu et al:: Polysaccharides from Liriopes Radix ameliorate streptozotocin-induced type I diabetic nephropathy via regulating NF-KB and p38 MAPK signaling pathways. BMC Complementary and Alternative Medicine 2014 14:156.

\section{Submit your next manuscript to BioMed Central and take full advantage of:}

- Convenient online submission

- Thorough peer review

- No space constraints or color figure charges

- Immediate publication on acceptance

- Inclusion in PubMed, CAS, Scopus and Google Scholar

- Research which is freely available for redistribution 